\title{
The Market for Firms: Market Signaling and Overpricing
}

\author{
Jerome Davis ${ }^{1}$, Hans Keiding ${ }^{2}$ \\ ${ }^{1}$ Dalhousie University, Halifax, Canada \\ ${ }^{2}$ Department of Economics, University of Copenhagen, Copenhagen, Denmark \\ E-mail:jerome.davis@dal.ca,hans.keiding@econ.ku.dk \\ Received March 18, 2010; revised June 4, 2010; accepted June 6, 2010
}

\begin{abstract}
In this paper, the pricing and sale of firms is approached from the owners' point of view. It is shown that there are very strong ex ante owner incentives to set prices of firm products or services below their shortterm profit maximizing levels, since low prices signal low costs and as a consequence a higher sales value of the firm. Buyers take this signaling into consideration, but irrespective of their countermoves, the equilibrium result may be a lowering of ex ante product prices, and an ex post market overvaluation of the firm. This model is utilized to suggest possible explanations to one of the more puzzling initial public offer (IPO) phenomena: the long run underperformance of IPO equities.
\end{abstract}

Keywords: Signaling, IPO Overpricing

\section{Introduction}

Sooner or later in the life of every successful owner of a firm comes the time when she (or her heirs) must sell the enterprise. This is true of the small corner retailer. It is true as well of the industrial entrepreneur; and nowhere is the problem more prominent than in the case of the venture capitalist whose livelihood depends on the sale of firms which she has nurtured over time. The structural characteristics of such a sale irrespective of the particular circumstances are, at first glance, simple. There is a lemons problem [1], which should lead to firm underpricing in the absence of market institutions countering adverse selection.

Yet, although owners selling their firms have a strong ex ante incentive to stress the quality of the firm being sold in order to sell most advantageously, there are few contributions to the literature dealing with owner sale strategies vis-a-vis other economic agents who have a direct or indirect economic interest in the sale. This is true of cases in which ownership is transferred directly to another economic agent in a private transaction as well as of of cases where the firm goes public.

In the extensive adverse selection literature associated with initial public offerings (IPOs), attention is focussed on financial markets and emphasis is placed on the role of intermediaries, the underwriters, and regulatory constraints $[2-4]$ in reducing the degree of seller-buyer asymmetric information. Several papers describe the role of underwriters [5-7] or auditors [8], in reducing asymmetric information and uncertainty.

Most of this literature is also not as much directed at IPO strategy as at what is termed IPO short-run underpricing - the frequency of large returns associated with the process of going public, indicating thereby that the underwritten equity issue was initially underpriced. This underpricing can lead to large jumps between introductory offer prices and "end of first day" [9]. In this approach the owner, here the issuer of the equity concerned, is typically seen as exchanging loss of revenue (due to underpricing) for the market information provided by the underwriting institutions [10]. Another adverse selection model is Rock [11] which interprets IPO short term underpricing as a means of avoiding the winner's curse phenomenon. But Rock essentially focusses on informed and uninformed buyers, whereas firm manager/owner's strategy is underplayed.

Similarly, signaling models involving firm sale seldom differentiate between firm owners (issuers of equity) and the underwriters who underwrite the IPO sale. Thus Grinblatt and Hwang [12], Allen and Faulhaber [13] and Welch [14] all advance variations of the thesis that IPOs are underpriced to investors, and leave them content. This increases the chance that investors will be receptive to the possibility of secondary offers. An exception to this ignoring of owner interests is Leland and Pyle [15], who hypothesize that the ratio of the equity retained by owners and the equity being publicly offered signals owner valuation of the equity on offer-the higher the 
ratio, the sounder the valuation behind the equity offering.

The problem of poor long term IPO share performance, particularly when paired with the performance of similar seasoned equities, is probably not unrelated to owner strategy. This long term underperformance has been reasonably well documented [9]. In this paper we suggest that the long term overpricing phenomenon may be linked to owner/manager IPO strategies as elaborated by our model.

We present a simple two period signaling model of firm sale in which the owners of a monopoly firm have a choice either to sell the firm or not. The focus is on the production costs of the firm to be sold. The seller signals low production costs; to make this signaling credible, the seller is also forced to set the prices of the firms products (or services) lower than would otherwise be the case. Such signaling also indicates that the potential profits accruing to new owners are higher than they otherwise would be, and sets a higher price for the firm. Even when the buyer takes into account that the firm has an incentive to indirectly understate its true costs, the final result may still be a higher price paid for the firm. This model is presented in the next section.

Despite the stringency of the assumptions behind this model, it is felt that it has relevance for IPOs generally. More particularly, the model can illuminate an alternative plausible reason why despite short-term underpricing, the performance of IPO firms over the long term is poor vis-a-vis performance of similar firms listed for alonger period of time. Sections 3 is devoted to this argument and examines the ramifications of our arguments in the context of other findings. In the final Section 4 we consider further extensions of the model as well as possible utilizations of the model in an empirical context.

\section{A model of Product Price Signaling Anticipating a Sale of the Enterprise}

In this section we preset a formal model where a firm is put on sale, partially or fully. The firm may influence the potential buyers by signaling success in the form of large turnover, something which in the short run may be achieved at the cost of educed profits, The proceeds from the sale are then assumed to compensate for this short-term reduction of income. We shall be interested in equilibrium behavior of the firm's initial owners as well as in the long-run consequences for the buyer and for the market as a whole.

The model has $K+1$ periods, where the first period, $t$ $=0$, represents the present data where the trading the firm is contemplated, and the remaining $t=1, \ldots, K$ periods represent the future. For simplicity we assume that what happens in the future is identical over all the $K$ periods. There are two agents in the model; agent 1 is a firm owner who makes the relevant business decisions and proposes to the potential buyer a share $\theta$ of the firm against a payment $P$. If the proposal $(\theta, P)$ is rejected, no sale takes place and the owner stays in business at $t=1$. If the proposal is accepted, the buyer will conduct the business from $t=1$. For simplicity we assume a discount rate of 1 . For the following presentation, we shall assume also that $\theta$ takes the value 1 , meaning that the owner does not retain any ownership after the sale, but partial sales might be incorporated with only minor changes of the formalism.

In order to provide an explicit reason why the owner wants to sell and the buyer to obtain ownership, we assume that incomes derived from running the firm in the future are risky and that the agents have a different attitude towards risk, the owner being risk averse and the buyer risk neutral. We choose a very simple formalization of seller's risk aversion, whereby future uncertain money flows are discounted at a rate $\rho<1$. A more standard approach to risk aversion could be taken at the cost of a less simple formalism.

We assume that the firm operates in a market which has some elements of competition, where not only the price, but also other factors, conveniently subsumed in a location parameter with values in the interval $[0,1]$, plays a role. We use the simple model of combined choice of location and price introduced by d'Aspremont, Gabszewicz and Thisse [16], cf. also Tirole [17]. There is a single product and consumers are evently distributed along the interval $[0,1]$, each consumer demanding exactly one unit of the commodity irrespective of its price. Transportation is costly, and the cost of a consumer buying the commodity at the price $p$ from a firm situated at the distance $x$ will be $p+t x^{2}$. We assume that there are two firms, where the owner of the first one contemplates a sale while other firm is a competitor, initially situated at $a$ and $1-b$, respectively, with $0 \leq a \leq 1-b \leq 1$.

For given choices of location $a$ and $b$ by the two firms, one can derive demand functions

$$
\begin{aligned}
& D_{1}\left(p_{1}, p_{2}\right)=\frac{1}{2}(1+a-b)+\frac{p_{2}-p_{1}}{2 t(1-a-b)}, \\
& D_{2}\left(p_{1}, p_{2}\right)=\frac{1}{2}(1-a+b)+\frac{p_{1}-p_{2}}{2 t(1-a-b)},
\end{aligned}
$$

for the two firms, and profit maximizing equilibrium prices $p_{1}^{*}$ and $p_{2}^{*}$ are given by

$$
\begin{aligned}
& p_{1}\left(a, b ; c_{1}, c_{2}\right)=\frac{2}{3} c_{1}+\frac{1}{3} c_{2}+t(1-a-b)\left(1+\frac{a-b}{3}\right), \\
& p_{2}\left(a, b ; c_{1}, c_{2}\right)=\frac{1}{3} c_{1}+\frac{2}{3} c_{2}+t(1-a-b)\left(1+\frac{b-a}{3}\right) .
\end{aligned}
$$

If firms maximize profits both with respect to location 
and in prices given the choices of location, then the final result will be maximal differentiation, that is $a=b=0$. In this case, the prices can be found as a weighted average of the unit cost plus a markup determined by the transportation cost,

$$
\begin{aligned}
& p_{1}^{*}=p_{1}\left(0,0 ; c_{1}, c_{2}\right)=\frac{2}{3} c_{1}+\frac{1}{3} c_{2}+t, \\
& p_{2}^{*}=p_{2}\left(0,0 ; c_{1}, c_{2}\right)=\frac{1}{3} c_{1}+\frac{2}{3} c_{2}+t
\end{aligned}
$$

so that prices and market shares are determined by the relative unit costs of the two competitors. The profits of the two firms are

$$
\Pi_{j}\left(c_{1}, c_{2}\right)=\left(p_{j}^{*}-c_{j}\right) D_{j}\left(p_{1}^{*}, p_{2}^{*}\right)>0, j=1,2 .
$$

Although firms choose the extreme positions in profit maximizing equilibrium, there may be reasons that one of the firms, say the first one, chooses $a \neq 0$. In the following, we assume that $c_{1}$, the true cost of firm 1 , is uniformly distributed in an interval $\left[c_{1}^{\min }, c_{1}^{\max }\right]$. For simplicity, the prior beliefs of the potential buyer are represented by the uniform distribution over this interval. We shall see that in order to get as high a sales price as possible for the firm, the owner might want to signal a lower $c_{1}$ than the one which is actually realized, even though this entails a smaller operating profit before the sale. This signaling is carried out by choosing a location closer to the competitor, so that equilibrium prices are lower, as they would have been in the case of a lower unit cost and location in $a=0$.

One might question the realism of our assumptions, both with respect to the lack of observability of $a$ and to the restriction of signaling to this parameter. On the one hand, there are cases where the assumptions are not too farfetched, since the potential buyer of the firm may be an outsider with limited knowledge of the details of the market. With regard to the limitation of signaling strategies to the location parameter, this can be explained by the existence of some delegation in decision making, whereby the owner decides upon $a$ but leaves day-to-day decisions (such as pricing) to local managers.

Returning to our model, if sellers of firms tend to disguise the true cost by signaling larger market share than what would be the case if the firm was not on sale, the potential buyer must take this behavior into account. Consider now the particular signaling strategy which consists in setting $a$ so that the market share will be as if cost had a lower level, say $\hat{c}_{1}$, and the location parameter was 0 , which means that $a$ is found from

$$
p_{1}\left(a, 0 ; c_{1}, c_{2}\right)=p_{1}\left(0,0 ; \hat{c}_{1}, c_{2}\right) \text {. }
$$

The resulting profit in firm 1 (for given $\hat{c}_{1}$ ) is

$$
\pi_{1}\left(c_{1}\right)=\left(p_{1}-c_{1}\right) D_{1}\left(p_{1}, p_{2}\right)
$$

where $p_{1}=p_{1}\left(a, 0 ; c_{1}, c_{2}\right)=p_{1}\left(0,0 ; \hat{c}_{1}, c_{2}\right)$ and $p_{2}=$ $p_{2}\left(0,0 ; \hat{c}_{1}, c_{2}\right)$, and the market share in this situation will be $x^{*}$ as given by

$$
p_{1}\left(0,0 ; \hat{c}_{1}, c_{2}\right)+t\left(x^{*}-a\right)^{2}=p_{2}\left(0,0 ; \hat{c}_{1}, c_{2}\right)+t\left(1-x^{*}\right)^{2},
$$

which is independent of the true $\operatorname{cost} c_{1}$. Notice that in accordance with our remarks above, we have assumed that the location choice different from 0 is not observed to the competing firm but observable to the costumers for the product which choose their supplier depending on this choice. We assume that although potential buyers of the firm are observing the market share $x^{*}$, it is not observed by the competitor, who may be assumed unaware of the sales plans of firm 1 and therefore presupposes the location choice of $a=0$.

The level $\hat{c}_{1}$ of cost which is simulated by the firm is given by the equation

$$
\int_{\hat{c}_{1}}^{c_{1}^{\max }} \frac{K \Pi_{1}\left(\eta, c_{2}\right)}{c_{1}^{\max }-\hat{c}_{1}} d \eta=\rho K \Pi_{1}\left(\hat{c}_{1}, c_{2}\right)
$$

Here the left-hand side is the highest price at which a buyer would pay for the firm given that the seller signals cost level $\hat{c}_{1}$; indeed, true cost after taking over can be inferred to be uniformly distributed in the interval $\left[\hat{c}_{1}, c_{1}^{\max }\right]$, and the value of to the risk neutral buyer is then equal to average profit in each of the $K$ future periods. The right-hand side gives the value to the seller of keeping the firm, so that for cost levels below $\hat{c}_{1}$ the firm owner prefer not to sell. For any $c_{1}$ greater than this level, it will be advantageous to sell at this price, as long as

$$
\Pi_{1}\left(c_{1}, c_{2}\right)-\pi_{1}\left(c_{1}\right) \leq \rho K\left(\Pi_{1}\left(\hat{c}_{1}, c_{2}\right)-\Pi_{1}\left(c_{1}, c_{2}\right)\right),
$$

which may be assumed to hold for all $c_{1}$ when $K$ is large enough.

We notice that the equilibrium exhibited above is a perfect Bayesian equilibrium in the game under uncertainty where seller type is given by true unit cost $c_{1}$; strategies of the seller are as described: If $c_{1}<\hat{c}_{1}$, then the firm owner keeps the firm and does no more; if $c_{1} \geq \hat{c}_{1}$, then at $t=0$, the seller chooses the location $a\left(c_{1}\right)$ by solving (2), thus signaling cost level $\hat{c}_{1}$, and subsequently sets a price $P$ given by the left-hand side of (3). which the location chosen for signaling purposes, and $P\left(c_{1}\right)$ is the proposed sales price of the seller with type $c_{1}$. Once the buyer gets the proposal, she may infer that cost is at least $\hat{c}_{1}$, but since the price charged takes this into account, accept the proposal is an equilibrium choice.

We may now state the main result of this section. 
Proposition. There is a perfect Bayesian equilibrium for the simple model of ownership change with market share signaling such that the sales price exceeds the value of profits after sale with probability $>1 / 2$.

Proof: We have seen above that the strategy of choosing for each $c_{1}$ the location $a\left(c_{1}\right)$ such that market share becomes $x^{*}$ together with the sales price as determined by (4) is a perfect Bayesian equilibrium. We may therefore concentrate on the second part of the proposition.

Let $\hat{\Pi}_{1}\left(c_{1}\right)=\Pi_{1}\left(c_{1}, c_{2}\right)=\left(p_{1}^{*}-c_{1}\right) D_{1}\left(p_{1}^{*}, p_{2}^{*}\right)$ be the true profits of the firm with cost $c_{1}$ given that location is chosen at $a=0$ (which is also the profits of the new owner). Inserting from (1) we get that

$$
\begin{aligned}
\Pi_{1}\left(c_{1}, c_{2}\right) & =\left(t-\frac{1}{3} c_{1}+\frac{1}{3} c_{2}\right)\left(\frac{1}{2}+\frac{p_{1}-p_{2}}{2 t}\right) \\
& =\frac{1}{2 t}\left(t-\frac{1}{3} c_{1}+\frac{1}{3} c_{2}\right)^{2},
\end{aligned}
$$

and differentiating with respect to $c_{1}$, we obtain that

$$
\frac{d \hat{\Pi}_{1}}{d c_{1}}=-\frac{1}{3}\left(1-\frac{c_{1}-c_{2}}{3 t}\right), \quad \frac{d^{2} \hat{\Pi}_{1}}{d c_{1}^{2}}=\frac{c_{1}}{9 t}>0,
$$

showing that $\hat{\Pi}_{1}$ is a strictly convex function of $c_{1}$. By Jensen's inequality, we have that

$$
\int_{\hat{c}_{1}}^{c_{1}^{\max }} \frac{\hat{\Pi}_{1}(\eta)}{\hat{c}_{1}-c_{1}^{\min }} d \eta>\hat{\Pi}_{1}\left(\int_{\hat{c}_{1}}^{c_{1}^{\max }} \frac{\eta}{\hat{c}_{1}-c_{1}^{\min }} d \eta\right) .
$$

Since $c_{1}$ is uniformly distributed in the interval $\left[c_{1}^{\min }, \hat{c}_{1}\right]$, its mean value is $\int_{c_{1}^{\min }}^{\hat{c}_{1}} \frac{\eta}{\hat{c}_{1}-c_{1}^{\min }} d \eta$, which equals its median. Multiplying by $K$ on both sides of (4), we have profits obtained from operating the firm after a sale if cost equals its mean value. Since this mean value is also equal to the median, the cases where the profits after sale do not cover the cost of purchasing the firm has a probability which exceeds $1 / 2$.

The result of the proposition shows that in more than half of the cases of a sale, the price paid is too high as compared to what can be earned after a sale. This can be seen as a weak version of long-run overpricing, in the sense that the after-sale performance of the firm is lower than what should be expected. This does not mean that the markets favorize the sellers, since indeed the price paid corresponds exactly to expected future profits. Therefore the overpricing is apparent rather than real, caused by the skewness of the profit distribution, but even so it is remarkable that a model exhibits this weak form of overpricing without any asymmetries on the buyer side.

\section{Discussion: Does Product Price Signaling Lead to IPO Overpricing?}

The hypothesis put forward in this paper is relatively straightforward: Poor long term IPO equity performance may be due to an initial overpricing which is in turn a function of owner/manager signaling of low costs through product pricing. Here we will briefly review the evidence of such overpricing, other plausible explanations as to why this overpricing occurs, and the nature of our own explanation.

Perhaps the most convincing evidence of poor long term IPO equity performance is that of Loughran and Ritter [9]. Their exhaustive study matched 4,753 IPOs with an equivalent number already listed firms for the period 1970-1990, and compares their relative performance over five years. They find that IPOs almost consistently (16 out of 20 five year cohorts) underperformed vis-a-vis their matching listing during their first five years, and by an average of 44 percent.

Loughran and Ritter take as the initial IPO equity price the end of first day prices which are on average 10 percent above offer prices in their sample. Taking this into account, the evidence for poor post-IPO market performance is still signlficant. A systematic revision of end of first day prices downwards by 10 percent, the findings are still robust (matching firms outperform IPOs in 14 out of 20 five year cohorts). Among the subsequent investigations, there are some indicating that underperformance may not be a universal phenomenon but is limited to special situations one finds Spiess and Affleck-Graves [18], who show that underformance tends to occur more offen in periods with many issues. Incidentally, their results which consistently show a fraction of underperforming IPOs above one-half fits well with the results obtaied in our model.

Explanations for long term IPO underperformance are several. Miller [19] argues that there is a self-sorting process in the purchase of IPOs; those buyers most enthusiastic buy the issue and more skeptical prospective buyers do not. In the longer term, this divergence of views disappears, and the prices of the equities fall. Shiller [20] advances an "impresario" hypothesis. In this interpretation IPO markets are subject to fads; IPOs are initially underpriced by underwriters (creating the impression of excess demand), and the underwriters, behaving like the stars of a rock concert, make the IPO an event [21]. Initial prices rise but then fall significantly over time. There is a certain overlap between Shiller's and Miller's explanation in that both argue that there is a creation of a "market frenzy" for IPO equities initially and that equities perform poorly thereafter. Yet the degree to which initial "market frenzy" is a sufficient explanation as to why these equities perform poorly is questionable. For example, the long term performance of seasoned market offerings, offerings without the frenzies 
associated with "hot" IPO offerings, is as disappointing as that of IPOs.

A more compelling explanation of this anomaly is that IPOs are timed to conform with "windows" of IPO opportunity and are therefore "overpriced" on their initial offering [22]. IPO issues tend to coincide with stock market peaks. Thus those listed equities paired with IPO equities in the Loughran and Ritter sample should also be experiencing a period of "overpricing". Yet despite this double overpricing of both IPO equities and listed equities, IPOs still underperform in the long run.

More recent explanations of the long-run underperformance phenomenon may be divided into those which refer to the data, pointing to systematical errors in the sampling of data which make a well-functioning market appear as biased, and those which focus on specific aspects of the sale as causing the observed underperformance. Among the contributions in the first class a prominent role is played by Shultz [23], who introduced the notion of pseudo market timing: The returns of the firms concerned may be evenly distributed above under below average, but due to the fact that more IPOs are issued when returns are high, the subsequent performance of the new IPOs will appear as underperforming, even though they were sold at their value. The findings were subsequently confirmed by others, e.g. Cheng [24].

Some support of our hypothesis that underperformance is related to signaling in the product market is furnished by the investigation of $\mathrm{Wu}$ and Kwok [25] who show that global IPOs underperform to a higher degree than purely local IPOs, a result which is consistent with a better knowledge of the background business conditions in the local IPOs (in our model corresponding to a smaller interval of possible values of $c_{1}$.

The influence of specific conditions of the firms being sold on subsequent performance has been investigated by Akhigbe, Johnston and Madura [26], who among other things point to the degree of regulation before sale as one of the important factors explaining underperformance. In [27], the role of growth opportunities is emphasized. Finally, the amount of cash raised during the IPO matters, as shown in [28]; IPOs raising more cash have a poorer long-run performance. Most of these features may be incorporated into our model, either through the choice of parameter values or in minor extensions, as for example allowing for a partial sale of the firm to show the influence of the amount of cash raised through the IPO. Thus, our model seems to be a useful ingredient of a future comprehensive theory of IPO underperformance.

The application of our dual signaling model to initial public offerings must remain tentative, our assumption being that the underlying economic logic of our model must be reflected in owner strategy, particularly in the case of venture capital IPOs which conform more closely to our assumptions. Direct proof of pre-IPO product or service underpricing is too complex a task to undertake in terms of sampling. Indeed, the very complexity of the phenomenon makes it difficult for underwriter, auditor, regulator and, ultimately, investor to assess prior to an IPO. This complexity is not altogether a disadvantage. Indeed one can claim that this very difficulty in ascertaining proper product or service prices can only reinforce the seller (issuer) with an incentive to underprice products and services as predicted by our model.

Evidence is therefore indirect and tentative, connecting our explanation to poor long-term post-IPO performance. At present this connection can only be suggestive. There are however various manners in which the relationships as forecast by our model can be tested in a more rigorous empirical manner.

Firstly, a smaller, more representative sampling can be utilized. Such a sampling could for example comprise direct venture capital to venture capital sales to each other. These direct sales are more significant than is generally realized. In the USA, for example, for 1995, there were 95 direct sales between venture capital firms worth $\$ 5$ billion as compared to 205 venture capital IPOs with a value of $\$ 8.2$ billions. Such a sampling will enable a better focussing on those firms which possess actual or potential monopolies as well as on their pricing policies.

Similarly, the question arises as to the interrelationship between regulatory requirements and IPO overpricing. To the degree that regulatory requirements make disceptive pre-IPO product price signaling difficult, one might expect more accurately priced IPO equities and a better aftermarket performance. As indicated earlier, pre-IPO requirements differ inter-nationally; in Europe, for example, IPO prices are more directly tied to booked values. To the degree that these different practices tend to prevent intentional or unintentional "accounting misstatements to market", records of long term IPO aftermarket performance might be different from the pattern in the United States if the arguments advanced in this paper are correct. This line of enquiry is underdeveloped at present.

\section{Conclusions}

The model presented in this paper with a view towards explaining IPO overpricing as a consequence of rational behavior in a signaling game involving prices of the final products is of course related to other models of signaling games applied to firms' behavior [29], where signaling is performed through the choice of rates of depreciation rather than as in our case through output prices, or [30], where the signal is the relation between debt and equity in a contract proposed by the firm to a potential creditor. These models and the present have in common that the signaling has a third-party effect, in our case an effect in terms of output prices generally set lower than they 
would otherwise have been.

Considered as a signaling model, what we have presented is somewhat crude; one might want to extend the model so as to include signaling of demand conditions, which in our model are assumed to be public knowledge. Also, it would be an obvious next step to include uncertainty on the side of the owner/manager with respect to buyer valuations. As mentioned earlier, the model has deliberately been kept at a very simple level, so that its basic idea, that product prices are set below the ordinary market equilibrium price due to considerations of cost signaling, emerges as clearly as possible. It goes without saying that several extensions of the model are possible, many of which would give only minor additional complication. This is however a topic for future research.

\section{References}

[1] G. Akerlof, "The Market for Lemons: Qualitative Uncertainty and the Market Mechanism," Quarterly Journal of Economics, Vol. 84, No. 3, 1970, pp. 488-500.

[2] J. Affleck-Graves and R. E. Miller, "Regulatory and Procedural Effects on the Underpricing of Initial Public Offerings," Journal of Financial Research, Vol. 12, No. 3, 1989, pp. 193-202.

[3] B. Chowdhry and V. Nanda, "Stabilization, Syndication, and Pricing of IPOs," Journal of Financial and Quantative Analysis, Vol. 30, No. 1, 1996, pp. 25-43.

[4] P. Hughes and A. V. Thakor, "Litigation Risk, Intermediation, and the Underpricing of Intial Public Offerings," Review of Financial Studies, Vol. 5, No. 4, 1992, pp. 709-742.

[5] H. Leland and D. Pyle, "Informational Asymmetries, Financial Structure, and Financial Inter-Mediaries," Journal of Finance, Vol. 32, No. 2, 1977, pp. 371-387.

[6] R. Beatty and J. Ritter, "Investment Banking, Reputation, and the Underpricing of Initial Public Offerings," Journal of Financial Economics, Vol. 15, No. 1-2, 1986, pp. 213-232.

[7] R. B. Carter, "Underwriter Reputation and Repetitive Public Offerings," Journal of Financial Research, Vol. 15, No. 4, 1992, pp. 341-354.

[8] S. Titman and B. Trueman, "Information Quality and the Valuation of New Issues," Journal of Accounting and Economics, Vol. 8, No. 2, 1986, pp. 159-171.

[9] T. Loughran and J. R. Ritter, "The New Issues Puzzle," Journal of Finance, Vol. 50, No. 1, 1995, pp. 23-51.

[10] D. P. Baron, "A Model of Demand for Investment Bank Advising and Distribution Services for New Issues," Journal of Finance, Vol. 37, No. 4, 1982, pp. 995-976.

[11] K. Rock, "Why New Issues are Underpriced," Journal of Financial Economics, Vol. 15, No. 1-2, 1986, pp. 187-212.

[12] M. Grinblatt and C. Hwang, "Signaling and the Pricing of New Issues," Journal of Finance, Vol. 44, No. 2, 1989 , pp. 393-420.
[13] F. Allen and G. Faulhaber, "Signaling by Underpricing in the IPO Market," Journal of Financial Economics, Vol. 23, No. 2, 1989, pp. 303-323.

[14] J. Welch, "Seasoned Offerings, Imitation Costs and the Underpricing of Initial Public Offerings," Journal of Finance, Vol. 44, No. 2, 1986, pp. 421-449.

[15] H. Leland and D. Pyle, "Informational Asymmetries, Financial Structure, and Financial Intermediaries," Journal of Finance, Vol. 32, No. 2, 1977, pp. 371-387.

[16] C. d'Aspremont, J. J. Gabszewicz and J.-F. Thisse, "On Hotelling's 'Stability in Competition'," Econometrica, Vol. 47, No. 5, 1979, pp. 1145-1150.

[17] J. Tirole, "The Theory of Industrial Organization," The MIT Press, Cambridge, 1988.

[18] D. K. Spiess and J. Affleck-Graves, "The Long-Run Performance of Stock Returns Following Debt Offerings," Journal of Financial Economic, Vol. 54, No. 1, 1999, pp. 45-73.

[19] F. Miller, "Risk, Uncertainty and Divergence of Opinion," Journal of Finance, Vol. 32, No. 4, 1977, pp. 1151-1168.

[20] R. J. Shiller, "Speculative Prices and Popular Models," Journal of Economic Perspectives, Vol. 4, No. 2, 1990, pp. 55-65.

[21] K. W. Hanley and J. R. Ritter, "Going Public", In: P. Newman, M. Milgate and J. Eatwell, Eds., The New Palgrave Dictionary of Money and Finance, Stockton Press, London, 1992, pp. 248-255.

[22] J. Lerner, "Venture Capitalists and the Decision to Go Public," Journal of Financial Economics, Vol. 35, No. 3, 1994, pp. 293-316.

[23] P. Schultz, "Pseudo Market Timing and the Long-Run Underperformance of IPOs," Journal of Finance, Vol. 58, No. 2, 2003, pp. 483-517.

[24] Y. Cheng, "Post-Listing Underperformance: Is it Really Bad to Move Trading Locations?" Journal of Corporate Finance, Vol. 12, No. 1, 2005, pp. 97-120.

[25] C. Wu and C. C. Y. Kwok, "Long-Run Performance of Global Versus Domestic Initial Public Offerings," Journal of Banking and Finance, Vol. 31, No. 3, 2007, pp. 609-627.

[26] A. Akhige, J. Johnston and J. Madura, "Long-Term Industry Performance Following IPOs," The Quarterly Review of Economics and Finance, Vol. 46, No. 4, 2006, pp. 638-651.

[27] D.-W. Chou, M. Gombola and F.-Y. Liu, "Long-Run Underperformance Following Private Equity Placements: The Role of Growth Opportunities," The Quarterly Journal of Economics and Finance, Vol. 49, No. 3, 2009, pp. 1113-1128.

[28] S. X. Zheng, "Market Underreaction to Free Cash Flows from IPOs," The Financial Review, Vol. 42, No. 1, 2007, pp. 75-97.

[29] M. Trombetta, "A Signaling Model of Cost Allocation between Periods," London School of Economics and Political Science, Unpublished Discussion Paper, 1997.

[30] R. Gertner, R. Gibbons and D. Scharfstein, "Simultaneous Signaling to the Capital and Product Markets," RAND Journal of Economics, Vol. 19, No. 2, 1998, pp. 173-190. 